\title{
Doença de Parkinson e Gravidez
}

\author{
Parkinson's Disease and Pregnancy: Case Report
}

Yukari Adachi ${ }^{1}$, Ana Paula Andrade Augusto ${ }^{2}$, Carlos Augusto Alencar Júnior ${ }^{2}$

\section{RESUMO}

\begin{abstract}
A doença de Parkinson caracteriza-se por tremores, rigidez muscular, bradicinesia e instabilidade postural e da marcha. Acomete todos os grupos étnicos, sem preferência sexual, freqüentemente aos 45-50 anos. O diagnóstico é essencialmente clínico. A associação com a gravidez é rara. A experiência com o binômio é escassa, permanecendo algumas questões sem resposta. Os autores descrevem um caso de doença de Parkinson e gestação com evolução satisfatória, apesar da piora clínica na gravidez. Apresentou elevação dos niveis pressóricos, alteração das enzimas hepáticas e oligoidrâmnio. Utilizou, por conta própria, selegilina até o terceiro mês e, posteriormente, amantadina. O neonato apresentou baixo peso, desconforto respiratório e icterícia, recebendo alta, sem outras complicações, no quarto dia de vida.
\end{abstract}

\section{PALAVRAS-CHAVE: Doença de Parkinson. Complicações da gravidez. Drogas na gravidez.}

\section{Introdução}

A doença de Parkinson é distúrbio neurológico basicamente constituído por desordens da motricidade, relativamente comum, que ocorre em todos os grupos étnicos, sem preferência por sexo. Incide em $0,2 \%$ dos individuos, mais freqüentemente por volta dos 45-50 anos, sendo incomum seu aparecimento antes desse período. Apenas $2 \%$ dos casos ocorrem antes dos 45 anos, sendo rara, por isso, a associação com a gravidez. O diagnóstico é essencialmente clínico, sendo os achados mais comuns os tremores, a rigidez muscular, a bradicinesia e a instabilidade postural e da marcha, podendo haver declínio da função intelectual ${ }^{1}$.

O tratamento é apenas paliativo, melhorando os sintomas e retardando a progressão natural da doença. Podem ser utilizados, para fins terapêuticos, os anticolinérgicos, a levodopa, a

\footnotetext{
${ }^{1}$ Residente de Ginecologia e Obstetrícia da Maternidade-Escola Assis Chateaubriand

${ }_{2}$ Serviço de Medicina Materno-Fetal da Maternidade-Escola Assis Chateaubriand

Maternidade-Escola Assis Chateaubriand

Serviço de Medicina Materno-Fetal

Departamento de Saúde Materno-Infantil

Universidade Federal do Ceará

Correspondência:

Carlos Augusto Alencar Júnior

Rua Dr. José Lourenço, 781 apto. 1004 - Meireles

60115-280 - Fortaleza - CE
}

amantadina, a selegilina e a bromocriptina.

Em virtude de sua infreqüente associação com a gestação a experiência clínica com o binômio é limitada. De acordo com a revisão de Hagell et al. de $1998^{2}$, haviam sido relatados 33 casos de gravidez em 24 pacientes com doença de Parkinson. Do total, 48\% não experimentaram nenhuma modificação no curso da doença durante a gravidez, $27 \%$ apresentaram piora dos sintomas, $6 \%$ tiveram alterações no pós-parto e as demais sentiram apenas repercussões transitórias, não-significativas. Parece haver algum risco de piora ou de início de sintomas de parkinsonismo durante ou logo após o parto, podendo corresponder à progressão natural da doença ${ }^{2}$.

Com o declínio da suspeita de significante contribuição genética na patogênese da doença de Parkinson $^{3}$ e com a tendência de postergar a maternidade para idades mais avançadas, passou a haver incremento de gestações nestas pacientes. Apesar disso, existem poucos dados relatados que permitam adequado aconselhamento às doentes. Muitas questões permanecem sem resposta, desde as repercussões da doença sobre a gravidez e vice-versa, até as implicações da terapia medicamentosa a ser utilizada nas gestantes e suas conseqüências para a mãe e o feto.

Os autores descrevem um caso de doença de Parkinson concomitante com a gestação, destacando a evolução materna, os resultados perinatais e a medicação utilizada. 


\section{Relato do Caso}

MJS, branca, 35 anos, primigesta, última menstruação em junho de 1998, encaminhada ao Serviço de Medicina Materno-Fetal da Maternidade - Escola Assis Chateaubriand no curso da 29a semana gestacional. Os exames ultra-sonográficos previamente realizados confirmavam a idade da gravidez. Apresentava história, desde os 14 anos, de distúrbio de motricidade, tremores progressivos, tendência a quedas, instabilidade postural, bradicinesia e alteração na fala e marcha. Relatava início de acompanhamento neurológico apenas em novembro de 97, quando foi diagnosticado ser portadora de doença de Parkinson. Como antecedentes familiares relatava dois irmãos, de 37 e 44 anos, e duas primas, de 42 e 51 anos, com a mesma sintomatologia. Após o diagnóstico iniciou o tratamento com levodopa, que, por apresentar efeitos colaterais (piora do quadro e coréia), foi substituído por selegilina ( $5 \mathrm{mg} / \mathrm{dia}$ ), com boa resposta à medicação. Ao engravidar, teve sua utilização desaconselhada devido aos insuficientes dados quanto à sua segurança durante a gravidez. Apesar disso, manteve o uso, por conta própria, até o terceiro mês de gestação, quando a suspendeu ficando então, sem medicação.

Durante o pré-natal, realizado inicialmente em outro serviço, evoluiu sem intercorrências até a $29^{a}$ semana, em dezembro de 1998, quando passou a apresentar elevação moderada da pressão arterial (PA), infecção urinária e piora neurológica, com intensificação dos tremores e dificuldade na marcha (após suspensão da medicação). Em virtude do agravamento do quadro, em janeiro de 1999, no curso da $33^{\text {a }}$ semana gestacional, foi internada na Enfermaria de Patologia Obstétrica da Maternidade - Escola Assis Chateaubriand, tendo evoluído com melhora clínica, recebendo alta após três dias de internamento.

Em fevereiro de 1999, passou a fazer uso de amantadina ( $200 \mathrm{mg} /$ dia) e, no $15^{\circ}$ dia de uso, com idade gestacional de 36 semanas, a paciente foi reinternada com infecção do trato urinário e moderada elevação dos níveis pressóricos, com média de PA de 140 x $100 \mathrm{mmHg}$. Apresentava ao exame ultra-sonográfico idade gestacional de 36 semanas, oligoidrâmnio (indice de liquido amniótico de $39 \mathrm{~mm}$ ), placenta grau II de Grannum, peso fetal estimado em $2.288 \mathrm{~g}$ e diminuição da movimentação fetal. Passou a apresentar picos hipertensivos de repetição e elevação das transaminases, sem queixas de iminência de eclâmpsia. Em decorrência do comprometimento obstétrico e devido às condições insatisfatórias para indução da parturição, foi submetida à cesariana no $6^{\circ}$ dia de internação.

Até o $2^{\circ}$ pós-operatório a paciente manteve níveis pressóricos elevados, com média de dois picos hipertensivos/dia e elevação de transaminases $(\mathrm{TGO}=137 \mathrm{mg} / \mathrm{dl}$ e $\mathrm{TGP}=100 \mathrm{mg} / \mathrm{dl})$, com redução progressiva de ambos. A paciente recebeu alta no $4^{\circ}$ dia de pós-parto, em boas condições clínicas.

O recém-nascido, sexo masculino, Apgar 8 e 9 no $1^{\circ}$ e $5^{\circ}$ minutos, respectivamente, foi considerado adequado para a idade gestacional, pesou $2.390 \mathrm{~g}$, com estatura de $47 \mathrm{~cm}$ e Capurro somático de 36 semanas. Nenhuma alteração da morfologia foi evidenciada nos exames neonatais realizados.

No $2^{\circ}$ dia de vida foi internado na unidade de terapia intensiva neonatal com quadro de desconforto respiratório de adaptação. Apresentou melhora progressiva, sendo encaminhado ao alojamento conjunto, para tratamento fototerápico por icterícia fisiológica. Recebeu alta no $4^{\circ}$ dia de vida sem outras intercorrências.

A mãe não manifestou desejo de amamentar, preferindo retornar ao uso da selegilina, de questionável segurança durante a amamentação $0^{4}$.

\section{Discussão}

A doença de Parkinson é caracterizada por tremores, rigidez muscular, bradicinesia e instabilidade postural e da marcha. O tremor aumenta com o estresse e é menos intenso durante os movimentos voluntários. Em geral, é restrito a um membro ou aos membros de um lado, antes de tornar-se generalizado. A rigidez e o aumento da resistência aos movimentos passivos são responsáveis pela postura caracteristicamente fletida ${ }^{1}$. Os sintomas mais incapacitantes são devidos à bradicinesia (diminuição dos movimentos voluntários e também dos automáticos, como o movimento pendular dos braços). Em estágio avançado observam-se imobilidade da face, fendas palpebrais aumentadas, pestanejar infreqüente, expressão facial fixa, diminuição da capacidade de engolir e modulação da voz. Tipicamente não existe fraqueza muscular nem alteração dos reflexos. Há dificuldade em levantar-se e iniciar a marcha e tendência a quedas ${ }^{1}$.

A substância negra cerebral sofre degeneração neuronal, devido ao esgotamento dopaminico, levando ao desequilíbrio entre a dopamina e acetilcolina, que são neurotransmissores normalmente presentes no corpo estriado. No início da doença não há necessidade imediata de medicação. Posteriormente, o tratamento busca restabe- 
lecer esse equilíbrio, com a administração de levodopa (precursor metabólico imediato da dopamina) ou por meio do bloqueio da acetilcolina (uso de anticolinérgicos) ${ }^{5}$.

Independente da droga a ser usada, o tratamento da doença de Parkinson é apenas paliativo, não cessando a progressão da degeneração neuronal. A escolha das drogas varia de paciente para paciente, podendo ser utilizada a amantadina (melhora em todos os aspectos), os anticolinérgicos (melhora dos tremores e rigidez), a levodopa (melhora em todos os sintomas), a selegilina (retarda a evolução da doença) e a bromocriptina (usada como um adjuvante da levodopa) $)^{5}$.

Baseado em estudos animais, tem sido recomendado que o uso da levodopa seja evitado durante a gravidez. Porém, entre 10 gestantes que a utilizaram, todas tiveram crianças saudáveis, nove completaram a gravidez sem intercorrências e apenas uma apresentou pré-eclâmpsia ${ }^{2}$. Segundo Hagell et al. ${ }^{2}$, os agonistas dopaminérgicos parecem seguros e não-associados com riscos durante a gravidez.

A amantadina, droga antiviral, produz melhora sintomática dos pacientes, provavelmente facilitando a liberação de dopamina a partir dos terminais dopaminérgicos intactos. Além disso, retarda a captação de volta para as terminações nervosas e exerce efeitos anticolinérgicos ${ }^{5}$. Existem relatos de malformações e complicações durante a gestação. Em ratos foi observado ser teratogênica na dosagem de $50 \mathrm{mg} / \mathrm{kg} / \mathrm{dia}^{6}$. Em humanos foi descrito um caso de anomalia cardiaca (ventrículo único com estenose pulmonar) em paciente que usou a droga no primeiro trimestre ${ }^{7}$. Em estudo de vigilância foram detectadas 5 anomalias maiores (somente 2 esperadas) entre 51 recém-nascidos expostos à medicação no primeiro trimestre ${ }^{8}$. Por outro lado, Golbe ${ }^{9}$ relatou que, em 4 gestações em que se utilizou a droga, 2 culminaram em aborto, uma apresentou sangramento no primeiro trimestre e a última teve préeclâmpsia.

A selegilina, inibidor altamente seletivo da enzima monoaminooxidase do tipo B, é eficaz no tratamento da doença de Parkinson em virtude da inibição do metabolismo intercerebral da dopamina, maximizando a eficácia da mesma. Em animais detectaram-se aumento da reabsorção e diminuição de fetos vivos em coelhas (50 mg/dia) e aumento no número de óbitos fetais em ratas $(16 \mathrm{mg} / \text { dia })^{2}$. Em 1998, Kupsch e Oertel ${ }^{4}$ descreveram um caso de uso da selegilina (10 mg/dia), associada à levodopa (500-600 mg/dia), durante toda a gestação, sem influência no resultado da gravidez ou no desenvolvimento fetal e neonatal. O recém-nascido não foi amamentado. Devido à limitada experiência clínica, a selegilina permanece contra-indicada durante a gestação e amamentação ${ }^{4}$.

A bromocriptina é agonista de ação direta do receptor dopaminérgico e é geralmente usada para complementar os esquemas terapêuticos que dependem principalmente da levodopa ${ }^{10}$. Largamente usada para tratamento da hiperprolactinemia, parece não estar associada a maior risco de perda fetal ou malformações na gestação ${ }^{11}$.

Com relação ao aleitamento, os dados são ainda menos concretos. Quase todas as drogas são excretadas no leite materno, porém em doses menores que os níveis séricos maternos. A dopamina é considerada contra-indicada, pois inibe a lactação. A amantadina parece ser excretada no leite em pequenas quantidades e não ter efeitos adversos na amamentação. Não se sabe, com certeza, se a levodopa e a selegilina são excretadas no leite materno ${ }^{2}$.

De acordo com a revisão de Hagell et al. ${ }^{2}$ encontram-se relatadas 33 gestações em 24 pacientes com doença de Parkinson. Do total, $48 \%$ não experimentaram nenhum tipo de alteração no curso da doença na gravidez, $27 \%$ apresentaram piora dos sintomas, $6 \%$ tiveram alterações no pósparto e as restantes tiveram alterações transitórias, não-significativas.

Segundo Golbe ${ }^{9}$, a exacerbação dos sintomas de parkinsonismo ou o aparecimento de novos sintomas é freqüente. A progressão durante a gravidez é maior que nos meses anteriores e posteriores à prenhez. Além disso, é comum não haver regressão dos sintomas após o parto.

No caso relatado, houve piora gradativa do quadro clínico na gravidez, talvez pela suspensão da medicação (selegilina) ou pela própria evolução da doença. Ocorreu melhora significativa dos sintomas após o parto e reintrodução das drogas.

Apesar do uso da selegilina no primeiro trimestre da gestação ( $5 \mathrm{mg} /$ dia) e da amantadina no último trimestre $(200 \mathrm{mg} /$ dia), o recém-nascido evoluiu satisfatoriamente, sem malformações aparentes e intercorrências significativas.

Não dispomos, na atualidade, de informações seguras que nos orientem sobre as mudanças da doença de Parkinson na gravidez ou sobre o tratamento mais indicado e sua eficácia nessas pacientes. Esperamos que novos estudos em animais e relatos venham a nos auxiliar na elucidação dos dilemas atuais. 


\section{SUMMARY}

Parkinson's disease is characterized by tremor, stiffness of the musculature, bradykinesia, and postural and march abnormalities. It attacks all ethnic groups, with no sex preference, frequently in the 45-50-year range. The diagnosis is essentially clinical. The association with pregnancy is rare. The experience with that association is scarse, some questions remaining without answer. The authors describe a case of Parkinson's disease and gestation with satisfactory evolution, in spite of the clinical worsening during pregnancy. The mother presented elevation of blood pressure levels, alterations of the hepatic enzymes, and oligohydramnios. She used, independently, selegiline until the third month, and, later on, amantadine. The newborn presented low weight, respiratory distress and jaundice, being discharged from the hospital, with no other complications, on the fourth day of life.

KEY WORDS: Parkinson's disease. Pregnancy complications. Drugs in pregnancy.

\section{Referências}

1. Beal MF, Fink JS, Martin JB. Parkinson's disease and other extrapyramidal disorders. In: Isselbacher KJ, Braunwald E, Wilson JD. Martin JB, Fauci AS, Kasper DL, editors. Harrison's Principles of Internal Medicine. 13 ${ }^{\text {a }}$ ed. New York: McGraw-Hill; 1994. p.2275-8.
2. Hagell P, Odin P, Vinge E. Pregnancy in Parkinson's disease: a review of the literature and a case report. Mov Disord 1998; 13:34-8.

3. Duvoisin RC. Etiology of Parkinson's disease: current concepts. Clin Neuropharmacol 1986; 9 Suppl $1:$ S3-21.

4. Kupsch A, Oertel WH. Selegiline, pregnancy and Parkinson's disease. Mov Disord 1998; 13:1756.

5. Stoelting, RK. Drogas usadas no tratamento da doença de Parkinson. Manual de Farmacologia e Fisiologia na Prática Anestésica. Porto Alegre: Artes Médicas Sul; 1997. p.295-8.

6. Lamar K, Calhoun FJ, Darr AG. Effects of amantadine hydrochlorine on cleavage and embryonic development in the rat and rabbit. Toxicol Appl Pharmacol 1970; 17:272.

7. Nora JJ, Nora AH, Way CL. Cardiovascular maldevelopment associated with maternal exposure to amantadine. Lancet 1975; 2:607.

8. Briggs GG, Freeman RK, Yaffe SJ. Drugs in pregnancy and lactation. $5^{\text {th }}$ ed. Baltimore: Williams and Wilkins; 1998. p. 33-4.

9. Golbe LI. Parkinson's disease and pregnancy. Neurology 1987; 37:1245-9.

10.Cedarbaum JM, Schleifer LS. Drogas para a doença de Parkinson, espasticidade e espasmos musculares agudos. In: Goodman LS, Gilman A, editores. As Bases Farmacológicas da Terapêutica. $8^{\mathrm{a}}$ ed. Rio de Janeiro: Guanabara Koogan; 1991. p.305-19.

11.Weil C. The safety of bromocriptine in long-term use: a review of the literature. Curr Med Res Opin. 1986; 10:25-51.

\title{
10 CONGRESSO BRASILEIRO SOBRE MATERNIDADE SEGURA E SAÚDE REPRODUTIVA
}

\author{
Período: 15 a 18 Novembro de 2000
}

\author{
Local: Brasília
}

\section{ORGANIZAÇÃO: SGOB}

\section{Tel.: (61) 245-3681}

